\title{
Attenuated Access: Accounting for Startup, Maintenance, and Affective Costs in Resource-Constrained Communities
}

\author{
Lucy Pei \\ University of California, Irvine \\ Irvine, USA \\ lpei@uci.edu
}

\author{
Roderic Crooks \\ University of California, Irvine \\ Irvine, USA \\ crooksr@uci.edu
}

\begin{abstract}
The term "digital divide" indexes a body of research at the intersection of digital technology and social equity, including research on inequality that criticizes and recapitulates the original concept. Based on a qualitative study at a community literacy center serving resettled refugees and immigrants, we show that the digital divide framework rests on a distributive logic, one that implies that distributing access to digital technology constitutes a form of social equity. Because this framework only considers valorized goods, skills, and uses, research has frequently ignored the startup, maintenance, and affective costs we found accompanied digital access for our participants. To account for these costs, we propose a theoretical adjustment to the digital divide framework, one where design is an act of configuring both costs and benefits together. We argue that considering such costs enables HCI researchers to engage more effectively with host communities in the noninnocent work of confronting inequity.
\end{abstract}

\section{Author Keywords}

Equity; social justice; digital divide; digital access; immigrants and resettled refugees

\section{CCS Concepts}

-Human-centered computing $\rightarrow$ HCI theory, concepts and models; Empirical studies in $\mathrm{HCI}$;

\section{INTRODUCTION}

The HCI community has a long-standing interest in the intersection of concerns about social justice and equity with digital technology (e.g. $[4,21,53,61])$. A digital divide is a commonly-used framework for research done at this intersection (e.g. [33, 65, 77]). Typically, a digital divide is defined as a deficit between two groups of people, where one group is lacking in some aspect of digital access. For example, Redmiles et. al. note that "Previous research has established the existence of a digital divide: an access, skill, and knowledge gap in digital literacy between lower- and higher- SES populations," [59]. Even when researchers do not use the term digital

\footnotetext{
Permission to make digital or hard copies of all or part of this work for personal or classroom use is granted without fee provided that copies are not made or distributed for profit or commercial advantage and that copies bear this notice and the full citation on the first page. Copyrights for components of this work owned by others than the author(s) must be honored. Abstracting with credit is permitted. To copy otherwise, or republish, to post on servers or to redistribute to lists, requires prior specific permission and/or a fee. Request permissions from permissions@ acm.org.

CHI'20, April 25-30, 2020, Honolulu, HI, USA

(C) 2020 Copyright held by the owner/author(s). Publication rights licensed to ACM. ISBN 978-1-4503-6708-0/20/04 . .\$15.00
}

DOI: https : //doi .org/10.1145/3313831.3376587 divide explicitly, the deficit framings it names are common. While it is important for research to identify inequities, we find that the framing of a digital divide obscures costs and harms unique to interventions seeking to help resource-constrained populations. A digital divide (or divides, if more than one has been diagnosed) functions according to a distributive logic: digital access becomes a good that can be distributed to both fix past harms and prevent future harms [18]. However, additional divides continue to appear with different permutations of deficits assigned to demographic groups [29, 74]. No matter how digital artifacts and skills are distributed, disparities that are portrayed as technical, rooted as they are in social inequalities, persist, making the digital divide a slippery framework [69]. We consider that the theoretical constructs of HCI itself may be limiting our means of addressing digital inequity. A digital divide framework lends itself to a constrained solution space of distributing digital access, which rarely produces equity. This paper shows how the framing of "closing" [46] digital divides through distribution of digital access is inadequate to account for the costs that come along with benefits to digital connectivity. We chose to center our paper around the digital divide concept because we seek to engage not only with the latest iteration or critique of the concept, but with the body of work as a whole. While there has been a proliferation of theoretical concepts and models that have amended the digital divide as it was originally defined [20, 29, 32, 69], we find the term useful for drawing together a long line of research [74]. We acknowledge the nuance that has been developed by subsequent research; however, we focus on an underlying issue that persists across these evolutions.

Based on qualitative research we conducted at a community literacy center in the US, we seek to reframe digital divides and acquisition of digital access as a bundle of costs and benefits. Through our analysis of over a year of observing and participating in resettled refugee and immigrant populations' acquisition of digital access, we find that digital divide framings work to hide a variety of costs to participants that come with the benefits of connectivity.

A digital divide framework is often applied to minoritized and resource-constrained communities, including the immigrant and resettled refugee community we study here $[1,15]$. With growing numbers in forced and willing migration around the world, a community of HCI researchers has begun to study and design with immigrants (e.g. [14, 35, 80]), undocumented immigrants (e.g. [5, 27, 30, 49]), and resettled refugees (e.g. [3, $15,16,36])$. We contribute to the empirical understanding of 
the unique challenges shared by these communities, especially those around language learning. At the same time, we use our empirical findings to question the digital divide and the logic of distributive access upon which it relies.

This paper makes significant contributions to research in HCI in two ways. First it contributes empirical fieldwork in an understudied context of community adult education with a resource-constrained population of resettled refugees and immigrants. Second, we contribute an analytical angle that is currently underutilized within the body of theory and models of digital divides and digital inequality: the lens of cost associated with newly gained access. This allows us to highlight the importance of a few cases of work that we term subtractive engagements, where technologists intervene to more appropriately configure the benefits and costs of access. Such engagements, which can provide crucial outcomes for members of resource-constrained communities, are foreclosed when costs are not explicitly considered in work at the intersection of technology and structural inequality. Our analytical angle also allows us to see that technological access always extracts value from its intended beneficiaries, therefore design engagements that seek to distribute access must always consider the configuring of costs as well as benefits.

\section{RELATED WORK}

\section{Regarding Digital Divides}

The concept of the digital divide originated in a 1995 survey by the US Department of Commerce, where certain populations were determined to be information "have nots" who lacked access to "the riches of the Information Age" [18, 51]. This concept has persisted over time and over different information and communication technologies (ICTs), from pre-Internet personal computers through Internet access, mobile devices, social media, and more. Divides have been identified at the level of individuals, households, schools, communities, countries, and regions. Early work focused on socio-demographic quantifications of the so-called digital divide and tended to portray access as a monolithic concept [74].

While digital divides work well as a framework for diagnosing inequalities, researchers have pointed out shortcomings in this framing. Policy researchers pointed out that for digital media, as well as older media, divides in "penetration" shrank without intervention as prices dropped [17]. Researchers criticizing the binary nature of a divide have documented nuances in desire to use ICTs and degrees of use not captured in the framework of a digital divide, painting the picture of a spectrum "ranging from the truly unconnected, to evaders and drop-outs, to intermittent users, to home broadband users" in the case of Internet access [7]. Researchers also located divides beyond physical access, such as Hargittai's identification of a "second-level digital divide" in skills and uses [32]. In a review of literature seeking to understand factors influencing "differentiated use," Sims finds that researchers reached a consensus attributing digital differences associated with social inequality to skills, literacies, and cultural or technical capital [20, 69]. Sims proposes instead a "differentiating practices" approach to understanding different groups' uptake of digital media, studying how digital media practices interact with other negotiations in an individual's presentation of identity in context [69].

In addition to missing many nuances, the digital divide hovers between theory and empirical reality. Many papers present digital divides as an empirical reality, backed up by statistics and other published work. Yet they are a metaphor and theoretical construct describing demographic differences in a normative light [69]. While the deficit model of a divide suggests additive solutions to address the issue, it does not lend itself to considering how we might subtract things and situations that are causing harm. Design for digital access is portrayed as being able to both fix past harms and prevent future harms, as prior critiques have pointed out [18]. Digital divide frameworks position technical intervention as a good, masking costs to the community being designed for and justifying intervention [69].

Digital divides do important work in diagnosing social inequity relating to digital technology. We continue to engage with this concept as encompassing the revisions and recapitulations that have followed it because following Sims's critique, we worry that merely updating to a preferred term leaves certain assumptions of the digital divide intact and reproduces structural inequality [68]. While prior advancements to digital divide literature have included the concept of expenses in maintenance [29, 76], the consideration of expenses is used to identify a new digital divide [29] or to explain an aspect of differential material access that leads to further inequalities in the skills, usage, and material outcomes of technology engagement [76]. Our work seeks instead to highlight costs that necessarily accompany newly gained digital access in interventions for social equity, addressing an underlying gap in the literature.

\section{Digital Divides in $\mathrm{CHI}$}

Within CHI proceedings and extended abstracts, the digital divide has consistently appeared since the early 2000s. This work has identified important social inequities tied to digital connectivity and reported on designs for digital access as a means to address inequalities. Here we seek to characterize the ways digital divides are used in HCI literature to push on how the framing constrains the way we address inequity. In a review of literature keyworded by the term "digital divide," we find that digital divide framings are used in HCI literature to construct a problem that also doubles as an opportunity for intervention with interface design and other HCI-related approaches. We show that digital divides, despite being diverse, always portray a difference between two specific groups, with one group being deficient in technology and sometimes in other aspects. Technology is typically proposed as a solution to mitigate harms from digital deficits.

Among CHI papers mentioning "digital divide" in the title, abstract, or as a keyword, the most common grouping of people puts "developing" groups are on the "other side," [2, 13, 34, 40, $41,42,46,58,67,71,75]$. Developing groups were specified as entire countries, or at the scale of regions and communities. Developing groups on the other side of a digital divide were often also described as rural. A smaller cluster of papers and authors named older adults as being on the "other side" [48, 
$50,63,64]$. Another cluster of papers portray a divide determined by socioeconomic status, particularly within the United States [26, 29, 59, 78]. While flexibly applicable to different populations, digital divides always do the work of positioning one group as deficient in a binary categorization.

Across all of the groups, the deficits portrayed were primarily focused on the general access to digital technology, including both hardware and particular software applications like social media [2, 13, 34, 46, 48]. More specifically, these technological deficits included possession of $[50,64,75]$, infrastructure for $[40,71,75]$, technical and language skills to use [13, 40, $59,67,75]$, comfort/willingness to engage with [13, 48], and ability to maintain digital technology [29]. Other deficits are often presented alongside these digital deficits. These include lack of libraries [46], information [34, 78], social capital [26, 78], diverse friends [26], schooling [41], agency and development [67], curricular material [34, 71], world language proficiency [42], security [59], and jobs [78]. One article pointed towards on the design side, noting certain groups did not receive sufficient attention from the HCI community [58].

Technological interventions of varying specificity are then proposed to mitigate harms that are presented as stemming from these deficits. For digital divides that are constructed between those behind on "development", harms are often portrayed as the perpetuation of poverty [67], stated as "barriers to economic empowerment," [41] and widened "economic gaps for future generations" as children are unable to "successfully compete in the global economy," [34]. Many papers describing divides between different groups portray the harms of a digital divide as missing out from the "technology and the benefits it can bring" [64, 65]. Papers about development specifically mention the "power of the Internet" [13] and the "information revolution" which has "improved our quality of life [in the First World]" [58, 75]. Papers addressing digital divides for older adults also point to a lack of connection as a harm $[48,50]$. More specific harms were also discussed, such as a lack of self expression [40], late and missed assignments for students [29], security and privacy breaches [59], incorrect job search information [78], and isolation [26].

Opportunities for design were presented throughout the papers reviewed, from generic suggestions to already-prototyped designs. Many papers reported usability suggestions as opportunities for design to address digital divides $[34,46,50,58$, $64,65,67]$. Non-interface design suggestions were commonly made $[29,41,42,75,78]$. In addition to design recommendations, several papers report on prototypes that were designed to help bridge a digital divide, such as a device to help elderly individuals communicate with family members [48], a printable surrogate computer use system [13], and an input device for Indic languages [40]. Theoretical suggestions [2] and implementation suggestions [71] were also included as ways to address digital divides.

While the framework of a digital divide can be useful in indexing work that aims to address disparities for minoritized communities, we hope to inspire HCI researchers and practicioners working toward equity and social justice [21] to reject deficit framings that mask the costs of digital access.

\section{Resettled Refugees and Undocumented Immigrants}

Recent work has begun to focus on the understudied populations of resettled refugees and undocumented immigrants. Much of this work has focused on designing novel artifacts with and for the population. Researchers have applied methods for codesign with teenage members of these populations [24, 56], designed ubiquitous computing applications to help with adjustment [3], and prototyped applications to help resettled refugees share information digitally [36]. Hsiao and Dillahunt looked specifically at how digital technology supports immigrant populations in building social capital, with recommendations for technology design [35]. Researchers have also turned to low-tech solutions to help migrant day laborers overcome emotional barriers to digital technology use [27, 28].

Some work has begun to study the role of digital technology in the lives of vulnerable resettled refugees $[15,16]$ and undocumented immigrants $[5,30,49]$. These studies have helped to illuminate ways in which technology can provide benefits by facilitating connection and communication $[5,15$, $16,30]$. Several studies also find ways technology can be harmful for these vulnerable populations by exposing them to surveillance $[30,49]$ and pressures to stay connected even when connection deepens trauma $[15,16]$. These papers have focused on a lens of security and drawn on more short-term interview data. We contribute to this small but important body of work with a longer-term engagement that brings theories of digital divides and digital access to bear rather than theories of security. Several papers also discuss the digital divide vis a vis resettled refugee communities; however they use it to report demographic differences in digital connectivity $[1,9,15,25]$.

\section{METHODS}

Data for this study was collected at a community literacy center in a Midwestern city in the US between 2017-2018 over 16 months. The first author was embedded at the literacy center as an English and technology teacher during the data collection period. It was understood among the staff and students that she was conducting research on digital connectivity for minoritized communities. She had become acquainted with key members of the organization through another research project in which the literacy center was a community partner. All participants in the study were recruited during classes. Observations and interviews were designed to be minimally disruptive to the normal functioning of class. Following other HCI papers using qualitative methods (e.g. [19, 38]), we draw on both interview and ethnographic observation data.

\section{Field Site}

The literacy center provided free English as a Second Language (ESL) classes for adults. Many students were recently resettled refugees, who were referred to the center by resettlement agencies. At the time of the study, the primary groups of resettled refugees were from Bhutan, the Democratic Republic of the Congo, Iraq, Afghanistan, and Syria. Some students had only experienced a few years of dislocation due to a recent conflict, while others came from regions of protracted conflict and had lived in a refugee camp for up to 20 years, such as those from Nepal [66]. Several students were asylum seekers 
from Venezuela. Other students had immigrated to care for their grandchildren, often coming from China and Russia.

Education and literacy levels varied, both in English and in the students' primary language. Some students had postgraduate degrees and professional careers while others did not complete elementary school and were not literate in their primary language. Most students were either looking for a job or working entry-level jobs. Our students commonly worked as housekeepers or kitchen staff at local hotels and restaurants. Students had varied goals for coming to class at the literacy center. Many wanted to learn enough English to function in daily life and find a job. Others wanted to improve academic English and hoped to attend community college or become recertified in their profession. An older adult mentioned that they considered coming to English class as much an opportunity to socialize as a learning opportunity.

The first author had become acquainted with the literacy center and some of its staff as a research assistant on a previous project in which the literacy center was the community partner. Upon getting back in touch with the literacy center, she learned that the literacy center had received a donation of several iPads but that the devices were locked in the teacher's office due to lack of bandwidth and confidence of teachers to use the technology with the students. We used the online flashcard application Quizlet to make class content available for digital practice. The first author uploaded images and recorded audio for vocabulary sets and ran weekly lunch-hour sessions at the literacy center so students could practice English on the iPads. The sessions evolved when students asked to use Quizlet on their own phones, and then asked for more general help with using their phones. Although the session was listed as "iPad class" on the schedule, it became a drop-in session where many students asked for help with their own devices while others continued to practice on Quizlet with the center's iPads. Putting class content on Quizlet made it possible for students who were not literate in English to practice outside of class time. Students with long bus commutes could practice on the bus, and students who could not make it to class for long periods of time could review at home. The drop-in technology class was able to fulfill the desire of the teachers at the center to help students both practice English online and become more technically literate. In addition to the "iPads class", the first author also taught the Advanced ESL class.

\section{Data Collection}

The primary data source for this paper is a set of three group interviews conducted during ESL classes with adult English language learners. Each group interview lasted between 30 minutes and 1.5 hours and was conducted in English. Interviews were conducted during class time in the classroom, with a separate activity prepared for students who did not want to be interviewed. None of the students who came to class on interview days opted not to be interviewed. We elected to conduct group interviews in English due to the ability of English language learners to aid each other in translation and communication in a common language [16]. 15 total students were interviewed, with 8 from the Intermediate level and 7 from the Advanced level. Participants' ages ranged from 23-80.

\begin{tabular}{lllr}
\hline Participant & Country of Origin & Age Group & English Level \\
\hline 1 & China & Over 60 & Intermediate \\
2 & D.R.C. & $30-60$ & Intermediate \\
3 & D.R.C. & $30-60$ & Intermediate \\
4 & Mexico & $18-30$ & Intermediate \\
5 & Mexico & $30-60$ & Intermediate \\
6 & Mexico & $30-60$ & Intermediate \\
7 & Philippines & $30-60$ & Intermediate \\
8 & Russia & Over 60 & Intermediate \\
9 & Afghanistan & $30-60$ & Advanced \\
10 & Brazil & $18-30$ & Advanced \\
11 & Iraq & Over 60 & Advanced \\
12 & Japan & Over 60 & Advanced \\
13 & Nepal & Over 60 & Advanced \\
14 & Russia & Over 60 & Advanced \\
15 & Venezuela & $30-60$ & Advanced \\
\hline
\end{tabular}

Table 1. Participants, recruited from Intermediate and Advanced ESL classes, came from a variety of countries and age groups.

Participants' countries of origin included Afghanistan, Bhutan, Brazil, China, the Democratic Republic of the Congo, Iraq, Japan, Mexico, the Philippines, Russia, and Venezuela. Participants ranged from having arrived in the US several months before the interview to being in the US for over 20 years.

We explained the purpose of the interview as well as how the interview results would be used. When necessary, we translated this information to students' native languages to ensure participants were fully informed before deciding if they would consent to be interviewed. We worked to ensure that participants would also benefit from the process of being interviewed. We introduced technology-related vocabulary during the beginning of the class, such that being interviewed allowed participants to practice the vocabulary. We took time during interviews to explain any vocabulary or grammatical questions that participants wanted help with.

These semi-structured interviews focused on how students accessed mobile technology, how they felt about mobile technology, and how they were using mobile technology. We did not collect any sensitive data or personally identifying information. The interview questions were approved by the supervising teacher at the literacy center for being comprehensible and appropriate to ask the students. All interviews were audio recorded and transcribed.

In addition to the interviews, we draw on detailed field notes taken while the first author was at the literacy center. In addition to 16 months of weekly "iPads class" sessions, the first author taught 42 two-hour advanced ESL classes and observed 40 classes taught by other teachers. When not in classes, the first author met with other teachers regarding technology issues. She recorded informal conversations about technology in the classroom and the students' technology use. Most interactions with students were conducted in English. For students who spoke minimal English, we used gestures, demonstrations, drawings, guesswork, translation through other students, and occasionally digitally mediated translation. This was the 


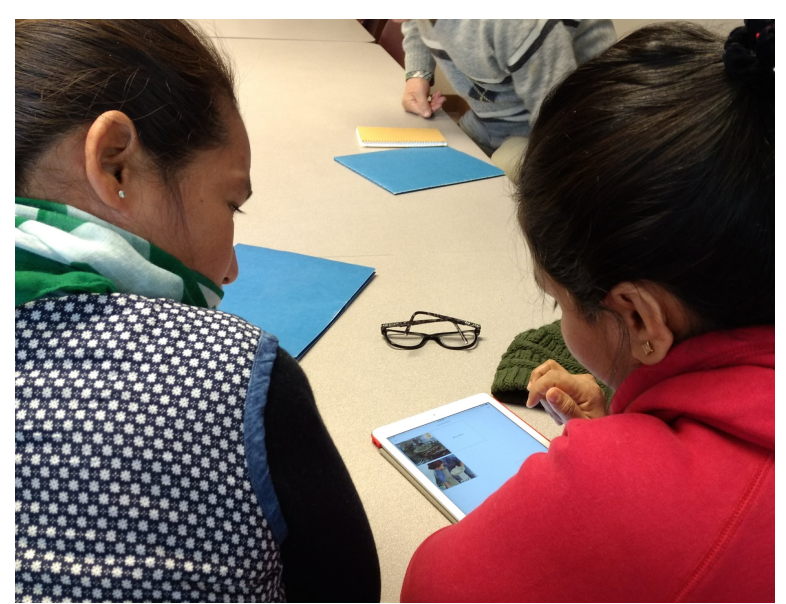

Figure 1. Students practice English with the literacy center's iPad during the technology class held by the first author.

norm for teachers at the center communicating with students who were less fluent at English. The first author also speaks Chinese (Mandarin) and Spanish fluently, so she had some in-depth conversations with students in their native languages. Throughout the paper, interview participants are referred to by their number in Table 1. Following Burrell [11], we take an expanded notion of the field site, one where participants and researchers together draw out the shifting boundaries of place and the complex negotiations of power relations.

\section{Data Analysis}

We conducted qualitative analysis on the transcripts of the interviews and the field notes from the ethnographic observations. We followed an iterative and inductive coding process $[38,60]$. Initial open coding included more granular themes such as "constant updating and learning." Subsequent iterations yielded higher-level codes such as "technology ages quickly", with themes being drawn out in the final iterations of coding to correspond with different kinds of costs that we encountered at the literacy center. An ethnographic approach beginning with open coding is appropriate for our contribution of retheorizing a framework such as the digital divide, as open qualitative approaches create "opportunities to examine the validity of existing theories of digital inequality and to provide grounds for revised theorizing," [69].

\section{FINDINGS}

We present findings around three high-level themes that emerged from the data to illustrate how gaining access and skills to use technology are not adequately theorized by the bridging of a digital divide. First, before any benefits to digital connectivity could be realized, participants faced high startup costs. Newly-gained access is not just about distributed devices, connectivity, or skills, as digital divide framings suggest, but also entails extractions through costs borne by users and their social networks [18]. Second, difficulties maintaining access show that the process of staying connected digitally is ongoing, not solvable with a one-time intervention. Finally, participants themselves expressed ambivalence and anxieties about the increasing place of smartphones and digital connectivity in their lives, dispelling the digital divide's directionality of distributing positive outcomes. The three categories of costs that emerged from our study are not exhaustive but reflect what we encountered. We share some detailed and contextualized examples from our fieldwork to illustrate each theme, while presenting categories of analysis and perspectives with which designers can think across different contexts.

As we worked with students to practice English on their and the school's digital devices, the students felt they benefited from being able to practice outside of class and use audio features. Students also expressed appreciation for digital technology in their daily lives, particularly for facilitating both diasporic and local connections. These findings reflect prior work on immigrant populations and digital technology $[5,12,15$, $16,54]$. However, we focus our analysis on the costs that came with digital access, which in the literature are often ignored. Coles-Kemp et. al.'s work is an exception, although they analyze negative consequences of the role of digital connectivity through the lens of negative security and "disbenefits" $[15,16]$. This trend of focusing on benefits is also reflected in wider ICTD literature, as Wyche et. al. point out: "While technologists have been quick to embrace the mobile phone as an ICT that can benefit the poor, there has been far less attention devoted to the problems inherent in these devices' design," [81]. In this paper we take the focus off of confirming findings around benefits of digital technology, not to deny these, but to contribute a more balanced account and draw attention to extractions from already resource-constrained populations.

\section{Startup Costs}

We use the category of startup costs to describe costs participants faced before being able to benefit at all from digital connectivity. Wyche et. al. found similar "antecedent conditions" for HCI and ICTD projects, noting that "if women struggle just to add airtime to their handsets, it is unclear how they can take advantage of [ICTD] services," [81]. Startup costs we observed were drawn not only out of participants themselves but also from their networks. Pooled resources such as those of the literacy center were drawn up in the process of gaining access for the first time.

\section{Hardware}

Hardware is a prerequisite for benefiting from access to digital connectivity. While some students, such as retired adults with no income, had few resources to be extracted for hardware purchase, extractions to enable initial access were subsidized through the participants' social networks. Many students at the literacy center received their devices from family members who had relatively greater resources. For example, several older, retired students reported receiving their smartphones from their children secondhand after the child bought a newer phone. P15, an asylum seeker from Venezuela, reported that he used an old backup phone that was at his brother's house.

The literacy center helped to subsidize the preliminary cost of hardware for students who could not afford to own a digital device. Staff at the center successfully applied for grants that were earmarked for technology hardware purchases, expanding the center's iPad collection. Preliminary expenses of 
hardware are often subsidized because of their visibility and one-time nature. Aside from the availability of used devices in the participants' personal networks, charitable donors preferred to sponsor the purchase of new digital devices for the literacy center, often in the frame of mind of promoting equity via device distribution.

\section{Internet Connectivity}

With a device in hand, participants still needed to connect to the Internet. Students had to pay for cellular data to practice English on their devices on the go, or had to pay for wifi to do so at home. While some students were able to afford this cost or share it among extended family members and even neighbors (P9), many students could not afford cellular data and did not understand how it worked. When teaching students how to practice English outside of class time using their own devices, we also warned students that using mobile data could be expensive, especially if students had a small data plan or no plan at all. We guided students to take advantage of free internet access at public libraries as one way to help students who did not have the resources to meet the preliminary expense of internet connection. Facilitating access would have certainly been more harmful than helpful if students accumulated mobile phone bills they could not afford. Wyche et. al. also found that their participants in Kenya owed high airtime fees to their telecom company, resulting in digital connectivity being far more beneficial to the company than the participants [81].

Data and storage were tradeoffs and extractions that we negotiated when trying to create digital opportunities for students to practice class materials. To avoid incurring high data costs for students, we debated providing content with videos that the students could download while on wifi and then watch later without wifi. But the students often had cheaper devices with less storage. Filling up the storage with videos would leave no room for other needed functions of their phones.

Allowing students to use the wifi at the literacy center was a point of contention among teachers and staff. Officially the policy was not to allow students to use the wifi, since overuse of the already modest-bandwidth internet at the center slowed down internet for teachers and staff. The startup costs of internet connectivity required navigating tradeoffs and the use of limited pooled resources.

\section{Advertisements}

Having overcome the preliminary costs of hardware acquisition and internet connection, students often still had to face the preliminary expense of advertisements before being able to benefit from their digital connectivity. Financially constrained students were not able to pay for the ad-free version of Quizlet, the platform we used to practice English at the center. There were also various free online resources for English learning that we wanted the students to benefit from, but these pages were saturated with advertisements.

As the first author was trying to guide the students on how to use the sites, she was confused about where to click to do the activity. The page was a maze of advertisements, as illustrated in Figure 2. It was difficult to figure out even for a native English speaker and someone with a degree in a

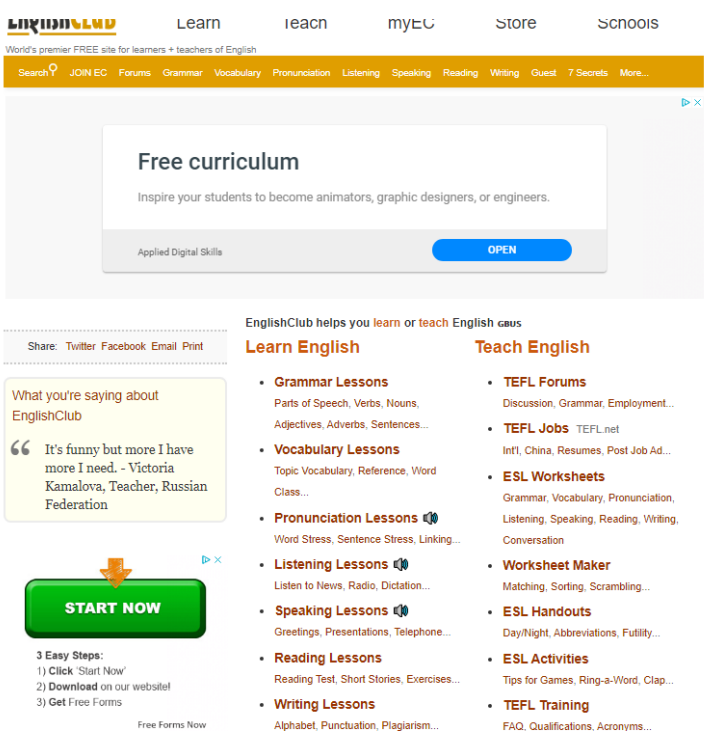

Figure 2. Advertisements made this free online English practice website difficult to navigate. Most students attempted to use the green Start Now button at the left of the screen, which was actually an advertisement.

computing related field. Advertisements extracted students' attention and accidental clicks. The costs of advertisements were also reflected in the work of Wyche et. al. in their finding that vulnerable Kenyan mobile users faced confusing ads that extracted their already constrained resources [81].

\section{Maintenance Costs}

Once achieved, digital access was easily lost. Jackson et. al. have argued for the foregrounding of maintenance and repair, particularly in resource-constrained contexts [39]. Our participants struggled with aging and broken devices, as Gonzales found with lower-SES university students [29]. Beyond being unable to pay for maintenance or an up-to-date device, participants had particular challenges stemming from their status as English language learners. Extractions were ongoing, as participants and their supporters had to continue to give up money, time, energy, and emotional capacity to keep using digital technology [18].

\section{Obsolescence}

Students struggled with owning obsolete technology that was defective and lagging. P7 shared how his laptop worked so slowly that he did not use it for anything important:

Sometimes it said warning your laptop needs to restart and you need to do like this but like I can't wait so I just power off. Yeah especially it's very noisy and it's loud. Sometimes it takes 30 minutes, one hour... I will not use that one [if] I have any important things because it takes me time... even if I connect to the Wi-Fi, it takes long before it starts, like for example I press the Google, I have to wait first at least 15 minutes...

P2 chimed in with frustrations about having to wait for hours at a time for his laptop to update. He also experienced delays with his phone: "When I used my phone is going slowly, slowing down too much, when I press you look like five seconds or 
10 seconds to go ahead, that is a problem." A student from Haiti stated that she did not have any interest in learning new skills on her phone because it was not a good phone. Many students received their phones as hand-me-downs from family members. Older devices quickly age out of functionality as smaller storage and computing capacity cannot run a much newer and heavier operating system, and battery life fails. An old hand-me-down phone that barely works for a few months can quickly become completely dysfunctional.

In addition to having to pay for maintenance and new(er) devices, participants also struggled with the constantly changing learning curve. As devices, operating systems, and interfaces change quickly, participants had to keep learning and re-learning new skills to continue to use the technology. Describing a second-order digital divide based on a deficit in skills [32] fails to illustrate that staying up-to-date with skills is an ongoing process. P14 expressed frustration with the need to keep up with ever-changing technology: "But it's one cell phone, other cell phone, but each every time, it need you learn it." Even after initial access was achieved via one particular version of software and hardware, the fast cycle of obsolescence meant students had to start again with purchasing a still-functional device and learning updated skills. At the literacy center level, obsolescence also hindered continued access to benefits of digital connectivity. The laptops at the literacy center, which consumed money and staff time to acquire, were rarely used because they often not operational. Teachers did not have spare time before class nor did they want to waste class time on watching laptops update.

\section{Social Support}

Participants often lost capacity to benefit from digital connectivity due to tenuous social support. Many participants relied on support from their social networks to stay connected. As they were often in need of help for both digital and nondigital ends, we found that participants were reluctant to ask for additional help. This meant long periods of disconnection for many of our students. Language barriers hampered their ability to problem-solve independently to regain connectivity, adding to the fragility of the participants' digital access.

Many participants experienced long interruptions to access and waited until their next class at the literacy center to get help with reconnection. P14 had gotten her tablet set up in Russian by her daughter. At one point P14 accidentally changed the language of her tablet to English. P14 became unable to use the tablet or change back the language since she could not read much English. She went without it for a week until she could make it to class and a teacher helped her revert the language. P14 told us she did not want to bother her busy daughter about her tablet troubles, even though she experienced many daily frustrations from the interrupted access. In another example, an older student from China told us that her daughter was very impatient, so she was afraid to bother the daughter about technological breakdowns. This student would often forget the steps to do something on her iPad. After we worked on one English practice set in class, she would not remember the steps to navigate to another set, so would wait until we met again. Another student, a middle-aged woman from Syria, had Quizlet as a recently visited tab on the internet browser on her phone. Once she used other apps on her phone and the icon was no longer there, she did not know how to return to the Quizlet site. This student told us that she had hoped to practice English on her phone while she was away from class for several weeks, but did not not want to ask her shorttempered teenage daughter for help. With relatively less techsavvy members in their network, and being in a position of feeling like they are always asking for help, participants were more likely lose connection for an extended period of time when something went wrong.

Some participants who had more prior experience with technology and were more fluent in English could manage interruptions to digital access on their own. For example, P3 told us, "Two years ago... my phone isn't working. I called the company. The company give me other phone. Now it's good, it's good. I have no problem." For most participants, however, maintaining access in the face of malfunctions in technology was more challenging. Participants had to rely on family members or resources at the literacy center to maintain their access. When P14's phone was not working, both she and her daughter had to make phone calls and store visits to fix the problem. This was stressful to P14, and extractive of her and her daughter's time and energy. Teachers often stayed after class or during breaks to provide impromptu help to students who had experienced a breakdown with their technology in this manner. In this way, costs to maintaining access were often distributed across a participant's support network.

In ICTD literature, intermediaries are individuals in a community who have more high-resource language literacy and technology literacy, or individuals from outside the community who possess those skills [22, 62]. The intermediary translates and manipulates the device for the user, and the user is newly able to access information or services [62]. The idea of an intermediary for a single technology device has been expanded in work by Dombroski et. al., as they consider how food assistance outreach workers serve as service mediators, enabling access to an entire service that is tied up in technological systems [22]. Extending the idea of brokers from ELL literature, researchers have documented how children of ELL parents act as information brokers to help their parents search online for information [82]. When acting as information brokers, children leverage their skills in technology literacy, search query formation, synthesis, evaluation of trustworthiness, and translation to help their parents find information that often has significant impact on the family's well-being [82]. We found that intermediation in many forms supported the digital access of our participants. For our participants, access demanded double the labor for a single transaction. From a digital divide perspective, this labor is unaccounted for. Reliance on intermediated access meant that connectivity was lost when social support was no longer available, and continued requests for intermediation felt costly to the participants' relationships with the people who helped them.

\section{Affective Costs}

After satisfying the initial costs to gain access and maintain it, participants gained many benefits including being able to 
connect with their families and friends abroad, find information, navigate and take the bus more efficiently, pay bills, and enjoy entertainment. However as previous studies have begun to show, the role of digital technology is not all positive. Coles-Kemp et. al. found participants felt controlled and overly reliant on their phones, with phones becoming a source of stress $[15,16]$. Digital divide frameworks paint the value of increased digital connectivity as a positive, especially for resource-constrained populations. Elsewhere in HCI literature researchers are attending to how people want to limit or leave certain uses of technology [6]. Our resource-constrained participants experience the same concerns about meaningless technology use and feelings of addiction or loss of control [44].

\section{Feeling of Addiction}

One theme that arose from our participants was a feeling of addiction and dependence on their phones. P7 brought up the topic on his own when we asked about what the students wanted to learn how to do on their phones. P7 asked how to limit his phone use in a day, mentioning that he felt addicted to his phone. He expressed that although he thought excessive phone use "is not good for me," he felt he could not stop. In response to this ask, the interviewer described apps that could monitor screen time as a way to limit phone use. Another participant in the group interview, P2, replied that he had already downloaded such an application but he still spends a lot of time on his phone and feels addicted to it, saying: "Yes, I use every day... I don't [use] my phone when I sleep only, but when I don't sleep, I use every time, at work... I send message [s]." One of the teachers mentioned that she and her husband had resolved to turn off their phones and put them away in a basket from dinnertime until the next morning. P2 replied, "So I can't do that. That's not possible to me." P7 expressed that he had tried to do something similar but could not commit to it. He replied "Maybe I will try that because I try to start but still cannot."

P14 described her feeling of dependence on her phone: "But now, I don't understand how [to] live without it, but it [has] all information, and all internet, all time, and wifi at home, but it's very complicated." Without naming addiction, she expressed a feeling of powerlessness with such heavy reliance on technology that she did not understand well and found difficult to keep up with. This aligns with prior work showing resettled refugee participants experienced a sense of dependency and lack of control as they felt there was "'no alternative' to being intimately connected with the mobile phone," [16].

Participants expressed appreciation for younger members of their family helping with technology. But they were also concerned that young people were becoming addicted to their screens. P14 was exasperated that her grandchildren would take her phone and hide it by the table to play games all day. P14's daughter did not normally allow the children to play games for long periods of time but P14 felt less able to control her grandchildren's screen time. Coles-Kemp et. al. also found that resettled refugee participants were concerned about "parenting children's mobile phone use," [16].

\section{Distraction}

An inability to concentrate and distraction from otherwise important tasks was a frequent concern of participants regarding their relationship with digital devices. Distraction from digital connectivity is well-documented in resource-rich contexts such as in large corporate workplace settings [45]. We find distraction to be a concern among our participants as well.

P7 gave the example of missing an appointment from being too engrossed in his phone, reflecting on his ambivalence towards phone use, as it both helped him and caused him to feel addicted and distracted.

It makes you addict, you know and you can't concentrate like for example let's say you're applying [for] a job and you have an appointment and if you miss it because you're very busy to your phone even though that your phone it helps you like to wake up because there is an alarm clock, but you're very busy using it ...playing a game so I don't know...

While acknowledging the benefits of digital connectivity such as through the alarm, P7 felt that there were costs in the form of being distracted and addicted to playing games, with consequences such as missing an appointment. After meeting the preliminary and maintenance costs, staying connected was costly of attention and often seemed to monopolize attention. P7 also mentioned that since his "mind [is] always on [the] phone," he often does not respond when his husband tries to talk to him in person, causing a strain on their relationship.

Participants grappled with the distraction cost that came with the benefits of digital study tools. P2 commented, "You lose something when you see notification, notification or a message. When you read a book, there is no notification." Being able to study interactively was a benefit of digital connectivity, but it came with the cost of distracting notifications and messages that hindered participants' progress in studying.

Distractions from phone use could be a cost to work performance. P2 mentioned that "sometimes it's not okay" that he is always on his phone because looking at the phone during work could put him in a bad mood: "Because when you work, there is some message, bad message if someone sent for you, sometimes you can be crazy. You take your time to read, to text someone when they send you a bad message."

Participants commented on the opportunity costs of spending so much of one's attention on digital devices. P8 lamented the way people miss out on looking at their surroundings and talking to other people:

When I take bus, I look on the people. They sit like a robot, it is very bad because we must talk with people, look out the window. Because a phone helps to me but I no all day look. No, we must watch sky, flowers, trees, dogs. In America very beautiful, there are very beautiful buildings... But we robots, look.

While also acknowledging that the phone helps her, she felt that other ways of interacting and attending to one's surroundings were important and was troubled at their loss. 
Interpersonal interaction was important to $\mathrm{P} 2$, and digital connectivity brought convenience at a cost to in-person connection. While P3 was appreciative that he could choose what movies to watch on his computer, $\mathrm{P} 2$ placed a more negative value on the solitary nature of viewing on a personal device instead of the television: "So I don't the movie on my laptop because when I look myself, I don't have fun but I look with my family, we have fun. " For P2, it was not worth the benefit of convenience to sacrifice in-person interactivity. Coles-Kemp et. al. also reported loss of intimacy as a result of the role of mobile phones in the lives of resettled refugee participants [16].

P3 and P7 both expressed concern about using the phone for entertainment purposes such as playing games or watching movies in contrast to productive phone uses such as paying bills and morally endorsed offline activities such as reading the Bible: "Because before during ...my ...free time I like to read a book like that, Bible, but now no because of the phone." These participants were concerned about the opportunity cost of spending time mindlessly on their phones.

\section{DISCUSSION}

Our findings demonstrated the stages of costs that accompany digital access. Most of our participants benefited from practicing English digitally, making and maintaining connections digitally, and other online activities. However, these benefits were accompanied by startup, maintenance, and affective costs. If the digital divide is a "gap" that can be "bridged" $[48,75]$ or "closed" [46] via digital access, this framing is inadequate to describe what we observed. As one respondent put it, "Maybe for me cell phone makes me addict but sometimes it helps me."

In the subsections that follow, we present a reframing of the digital divide to help account for the costs we observed in the findings from our fieldwork. Rather than intervening to "bridge" or "close" a gap, we propose designers frame engagements aimed at equity and social justice as a configuration of both costs and benefits among participants and their social networks. Explicit acknowledgement of costs in engagements aimed at social good and equity requires us to grapple with the non-innocence of even the most well-intentioned and considerate interventions. Grappling with this non-innocence should not discourage engagement with minoritized communities but rather challenge designers to more carefully continue addressing the real social inequities identified by digital divide literature [31]. Ultimately we suggest that evaluation of whether benefits are worth the costs should be an ongoing, deliberative calculation made by participants themselves, a process that can be supported by evolving HCI methods.

\section{Design as Configuring Costs and Benefits}

As we showed in the related work, digital divides are often used within the HCI community to frame an opportunity for design, as an entry point and justification for intervention. Dombrowski et. al. summarize the importance of framing problems in design for social-justice work: "The act of defining a problem simultaneously creates the acceptable parameters by which they can be addressed (i.e., solutions that contend with the problem) by narrowing the focus of the potential design solutions," [21]. Continuing to use a digital divide framework to define the problem when engaging with minoritized communities constrains the kinds of approaches and focuses designers may take. We support designers engaging to reduce inequity, but rather than intervening to deliver "solutions" against a deficit, we urge designers to view their work as configuring both costs and benefits. Prior work has shown the extractions of labor [18], the distributions of benefits that amplify social inequality [81], and the negative security [16] that come with digital connectivity for minoritized populations. For innovation even in resource-rich contexts, Suchman and Bishop point out that "innovation and change are inevitably costly undertakings, and require associated commitments to their ongoing, long-term development," [70]. We push this further to encourage designers to engage with costs as a necessary part of gaining and maintaining access. We hope designers will be mindful of the costs distributed, while being in open dialogue with participants about such costs, rather than ignoring, diverting, or otherwise failing to acknowledge them as an inherent part of intervention. Rather than framing intervention as a way to distribute good to disadvantaged populations, designers concerned with equity can honestly acknowledge the startup, maintenance, affective, and other costs that necessarily come with digital access. In the domain of privacy, privacy calculus considers costs and benefits at an individual decision-making scale, e.g. [10]. The consideration of both costs and benefits makes the act of disclosure value-neutral; similarly, we seek to highlight that distributing digital access is not inherently beneficial.

When approaching design as a configuring of costs and benefits, it is important to consider how costs may be configured across a network. In these cases costs may be less apparent because they are extracted from the individual's network rather than the individual themselves. Most of our participants were only able to achieve benefits from sustained digital connectivity because people in their network subsidized various stages of costs. Many of the participants' children, other family members, and friends provided financial support, secondhand devices, time, energy, and emotional support to meet the costs of digital access. These findings are similar to prior work on intermediated access $[22,62,82]$. While the ability for costs to be subsidized was helpful for participants accessing benefits, they often felt discomfort at owing so much to people in their networks. This caused longer interruptions to access, such as when participants did not want to bother family members for help when they encountered a problem or forgot how to do something. Designers need to recognize and acknowledge that even when diverted across a network, costs are a necessary part of design interventions. Such networked configurations of costs should be made visible and explicit.

Reconceptualizing digital divide frameworks moves us away from focusing on additive solutions. Pei and Nardi proposed that sustainable impact in design with resource-constrained communities could be improved with an assets-based approach to design, where minimizing novelty and maximizing the use of existing community assets lessens the high costs of additive interventions [55]. The shift to focusing on costs also allows for subtractive engagements which are foreclosed by a digital divide framework as a problem definition. Pierce 
has advocated for the "intentional negation" or "undesign" of technology as an active response that designers can take regarding "concerns with the limitations and negative effects of technology," [57]. As an example of how design can work to configure costs, Wyche et. al. created videos to help firsttime, low-income mobile users unsubscribe from "premium services" that resulted in costly consumption of their airtime minutes [81]. This subtractive engagement would not follow from a framing that placed the participants as deficient on the "other side" of a digital divide, but ultimately was a more helpful intervention for the participants.

\section{Non-Innocent Engagement}

It can be easy to consider costs associated with work for social good as a reason to not engage, or to divert funds to different opportunities. It is difficult to get funding to do charitable work to help a resource-constrained community, so acknowledging costs to the community is difficult. We need to be more transparent and recognize that interventions are always non-innocent, even when well-intentioned, done with care, welcome by the community, and delivering desirable benefits $[31,47]$. Our hope in pointing out the costs that come with digital access is not for designers to stop engaging with minoritized communities or to discount the work of researchers who have used the framework of digital divides. Rather we want to push further the work that scholars have done on diagnosing real and pressing inequities. Designers can express care for minoritized communities and a desire to ease very real suffering and inequities while recognizing that care also involves engaging with "the unhappy affects of staying in the trouble" [47]. Confronting the costs that come from one's efforts to be helpful can be uncomfortable and disrupts a narrative that emphasizes the good in technology for social good [53]. Working through uncomfortable affect and continuing to engage with minoritized communities are necessary to more deeply work toward "a common livable world" [31].

Sambasivan notes that "it takes humility and even detachment from pet ideas" to engage with "tough questions ... in technology-for-social-good projects," [61]. One of the questions she poses is "What should we do if there are unanticipated negative impacts?" We ask designers to engage with this not as a hypothetical but as an inherent part of of a more humble design practice. Costs should not automatically deter engagement but should be configured consciously and conscientiously as a necessary part of the design process.

\section{Evaluating Costs and Benefits}

The unique ways in which minoritized communities may be constrained in various resources (e.g. financial, attentional, emotional, etc.) poses the question, how do we know whether benefits are worth the costs in a design engagement? Ultimately we advocate for designers to enroll participants themselves in determining what kinds of benefits they want and what costs they think they should pay for them. This entails making costs transparent to participants, including ways costs may be subsidized by the participants' networks. Such determinations also need to be ongoing, as different opportunity costs and changes in other aspects of participants' lives may result in a different willingness to continue to pay certain costs for certain benefits. Crooks presents an example of this in the form of a town hall discussion where students who labored to provide and maintain access to a one-to-one tablet program in a minoritized school evaluated the costs and benefits of their digital access together [18].

Future work needs to find ways to bring HCI design methods and theoretical contributions for designing with minoritized and resource-constrained communities (e.g. [4, 14, 21, 23, 37, $53,55,61,72,73,79])$ together with a framing of design that explicitly acknowledges costs. One area that would be particularly rich for methodological evolution is the ongoing evaluation of costs and benefits by participants, and how this evaluation feeds into the design process. Erete et. al. have discussed both the importance and difficulty of collaborating with community members when setting goals for the outcome of a design intervention [23]. Participatory methods such as collaborative prototyping and scenarios can be adapted to include an explicit focus on configuring costs and evaluating costs against benefits $[8,43]$. Future deployments of such methods in situ will help to refine how design as configuring costs and benefits can engage with issues of equity and digital connectivity beyond divide and deficit frameworks.

\section{CONCLUSION}

This paper argues for a reconsideration of the digital divide, a popular and multidisciplinary concept that has been useful for talking about social inequities and technology. The digital divide surely owes some of its success to the way it both acknowledges the persistence of inequality and raises hope for its amelioration via access to powerful and seductive technologies. Tampering with such a pervasive and long-lived idea is a risky proposition: the digital divide has usefully served to draw attention to the way that benefits of digital access have frequently conformed to historical topographies of power and privilege. Likewise, the digital divide framework has given many educators and technologists a means to enact a vision of a more egalitarian world. Ultimately, our argument to the HCI community is hopeful. Given its many decades of experience in understanding how technology and people relate and its proven commitment to exploring the needs of minoritized communities, $\mathrm{HCI}$ is a field uniquely positioned to retool and refine the promises of digital connectivity. As Olson and Kellog write in a survey of nearly three decades of HCI research, "The higher purpose of HCI, of course, has always been understanding people and their contexts, how technology interacts with both, and how and to what extent it is possible to adapt technology to people, to their work, play, and aspirations - rather than the other way around" [52]. Our work here reaffirms a central commitment of $\mathrm{HCI}$ research, the desire to support meaningful community in any form it might take, using the always changing variety of computational tools and platforms available to support learning, social equity, and human flourishing.

\section{ACKNOWLEDGMENTS}

We thank the students, teachers, and staff at the literacy center for sharing their thoughts and spending time to engage with us. We also thank Bonnie Nardi, Philip Garrison, and the Evoke $\mathrm{Lab}$ and Studio for their advice, support, and feedback. 


\section{REFERENCES}

[1] Khorshed Alam and Sophia Imran. 2015. The digital divide and social inclusion among refugee migrants: A case in regional Australia. Information Technology \& People 28, 2 (June 2015), 344-365. DOI : http://dx.doi .org/10.1108/ITP-04-2014-0083 2019-08-09.

[2] Arvind Ashok and Christian Beck. 2007. Using activity theory to develop a design framework for rural development. In CHI '07 extended abstracts on Human factors in computing systems - CHI '07. ACM Press, San Jose, CA, USA, 2255. DOI : http://dx.doi.org/10.1145/1240866.1240990 2019-07-11.

[3] Jennifer Baranoff, R. Israel Gonzales, Jay Liu, Heidi Yang, and Jimin Zheng. 2015. Lantern: Empowering refugees through community-generated guidance using near field communication. In Proceedings of the 33rd Annual ACM Conference Extended Abstracts on Human Factors in Computing Systems. ACM, 7-12. 2019-07-18.

[4] Shaowen Bardzell. 2010. Feminist HCI: taking stock and outlining an agenda for design. In Proceedings of the 28th international conference on Human factors in computing systems - CHI '10. ACM Press, Atlanta, Georgia, USA, 1301. DOI:

http://dx.doi.org/10.1145/1753326.1753521 2019-09-09.

[5] Luis Fernando Baron, Moriah Neils, and Ricardo Gomez. 2014. Crossing new borders: computers, mobile phones, transportation, and English language among Hispanic day laborers in Seattle, Washington. Journal of the Association for Information Science and Technology 65, 1 (Jan. 2014), 98-108. DOI :

http://dx.doi.org/10.1002/asi.22949

[6] Eric P.S. Baumer, Phil Adams, Vera D. Khovanskaya, Tony C. Liao, Madeline E. Smith, Victoria Schwanda Sosik, and Kaiton Williams. 2013. Limiting, leaving, and (re)lapsing: an exploration of facebook non-use practices and experiences. In Proceedings of the SIGCHI Conference on Human Factors in Computing Systems - CHI '13. ACM Press, Paris, France, 3257. DOI : http://dx.doi.org/10.1145/2470654.2466446 2019-08-28.

[7] Eric P.S. Baumer, Morgan G. Ames, Jenna Burrell, Jed R. Brubaker, and Paul Dourish. 2015. Why study technology non-use? First Monday 20, 11 (Nov. 2015). DOI : http://dx.doi .org/10.5210/fm.v20i11.6310

[8] Erling Björgvinsson, Pelle Ehn, and Per-Anders Hillgren. 2010. Participatory design and "democratizing innovation". In Proceedings of the 11th Biennial Participatory Design Conference on - PDC'10. ACM Press, Sydney, Australia, 41. DOI : http://dx.doi.org/10.1145/1900441.1900448

[9] Caitlin G. Bletscher. 2019. Communication Technology and Social Integration: Access and Use of
Communication Technologies Among Floridian

Resettled Refugees. Journal of International Migration and Integration (March 2019). DOI :

http://dx.doi .org/10.1007/s12134-019-00661-4

[10] Nadine Bol, Tobias Dienlin, Sanne Kruikemeier, Marijn Sax, Sophie C Boerman, Joanna Strycharz, Natali Helberger, and Claes H de Vreese. 2018. Understanding the Effects of Personalization as a Privacy Calculus: Analyzing Self-Disclosure Across Health, News, and Commerce Contexts. Journal of Computer-Mediated Communication 23, 6 (Nov. 2018), 370-388. DOI : http://dx.doi.org/10.1093/jcmc/zmy020

[11] Jenna Burrell. 2009. The Field Site as a Network: A Strategy for Locating Ethnographic Research. Field Methods 21, 2 (May 2009), 181-199. DOI:

http://dx.doi.org/10.1177/1525822X08329699

[12] Jenna Burrell and Ken Anderson. 2008. 'I have great desires to look beyond my world': trajectories of information and communication technology use among Ghanaians living abroad. New Media \& Society 10, 2 (April 2008), 203-224. DOI : http://dx.doi.org/10.1177/1461444807086472

[13] Aditya Chand and Anind K. Dey. 2006. Jadoo: a paper user interface for users unfamiliar with computers. In CHI 'O6 extended abstracts on Human factors in computing systems - CHI EA '06. ACM Press, Montreal, Quebec, Canada, 1625. DOI :

http://dx.doi.org/10.1145/1125451.1125747 2019-07-15.

[14] Alexander Cho, Roxana Herrera, Luis Chaidez, and Adilene Uriostegui. 2019. The "Comadre" Project: An Asset-Based Design Approach to Connecting Low-Income Latinx Families to Out-of-School Learning Opportunities. In 2019 CHI Conference on Human Factors in Computing Systems Proceedings. ACM, Glasgow, Scotland, UK, 14. 2019-03-18.

[15] Lizzie Coles-Kemp and Rikke Bjerg Jensen. 2019. Accessing a New Land: Designing for a Social Conceptualisation of Access. In Proceedings of the 2019 CHI Conference on Human Factors in Computing Systems - CHI '19. ACM Press, Glasgow, Scotland Uk, 1-12. DOI : http://dx.doi .org/10.1145/3290605.3300411 2019-08-05.

[16] Lizzie Coles-Kemp, Rikke Bjerg Jensen, and Reem Talhouk. 2018. In a New Land: Mobile Phones, Amplified Pressures and Reduced Capabilities. In Proceedings of the 2018 CHI Conference on Human Factors in Computing Systems - CHI '18. ACM Press, Montreal QC, Canada, 1-13. DOI:

http://dx.doi.org/10.1145/3173574.3174158 2019-04-09.

[17] Benjamin M. Compaine (Ed.). 2001. The digital divide: facing a crisis or creating a myth? MIT Press, Cambridge, Mass. 
[18] Roderic N. Crooks. 2019. Times Thirty: Access, Maintenance, and Justice. Science, Technology, \& Human Values 44, 1 (Jan. 2019), 118-142. DOI: http://dx.doi.org/10.1177/0162243918783053 2018-12-17.

[19] Débora de Castro Leal, Max Krüger, Kaoru Misaki, David Randall, and Volker Wulf. 2019. Guerilla Warfare and the Use of New (and Some Old) Technology: Lessons from FARC's Armed Struggle in Colombia. In Proceedings of the 2019 CHI Conference on Human Factors in Computing Systems - CHI'19. ACM Press, Glasgow, Scotland Uk, 1-12. DOI :

http://dx.doi.org/10.1145/3290605.3300810

[20] Paul Dimaggio, Eszter Hargittai, Coral Celeste, and Steven Shafer. 2004. Digital inequality: From unequal access to differentiated use. Social Inequality (2004), $355-400$.

[21] Lynn Dombrowski, Ellie Harmon, and Sarah Fox. 2016. Social Justice-Oriented Interaction Design: Outlining Key Design Strategies and Commitments. In Proceedings of the 2016 ACM Conference on Designing Interactive Systems - DIS '16. ACM Press, Brisbane, QLD, Australia, 656-671. D0I :

http://dx.doi.org/10.1145/2901790.2901861 2019-09-04.

[22] Lynn Dombrowski, Amy Voida, Gillian R. Hayes, and Melissa Mazmanian. 2012. The labor practices of service mediation: a study of the work practices of food assistance outreach. In Proceedings of the 2012 ACM annual conference on Human Factors in Computing Systems - CHI'12. ACM Press, Austin, Texas, USA, 1977. DOI : http://dx.doi.org/10.1145/2207676.2208342 2019-03-21.

[23] Sheena Erete, Aarti Israni, and Tawanna Dillahunt. 2018. An intersectional approach to designing in the margins. Interactions 25, 3 (April 2018), 66-69. DOI : http://dx.doi.org/10.1145/3194349 2019-09-14.

[24] Karen E. Fisher, Ann Peterson Bishop, Lassana Magassa, and Phil Fawcett. 2014. Action!: codesigning interactive technology with immigrant teens. In Proceedings of the 2014 conference on Interaction design and children - IDC '14. ACM Press, Aarhus, Denmark, 345-348. DOI : http://dx.doi.org/10.1145/2593968.2610488

[25] S. M. Gifford and R. Wilding. 2013. Digital Escapes? ICTs, Settlement and Belonging among Karen Youth in Melbourne, Australia. Journal of Refugee Studies 26, 4 (Dec. 2013), 558-575. DOI :

http://dx.doi.org/10.1093/jrs/fet020

[26] Eric Gilbert, Karrie Karahalios, and Christian Sandvig. 2008. The network in the garden: an empirical analysis of social media in rural life. In Proceeding of the twenty-sixth annual CHI conference on Human factors in computing systems - CHI '08. ACM Press, Florence, Italy, 1603. DOI : http://dx.doi.org/10.1145/1357054.1357304 2019-05-29.

[27] Ricardo Gomez, Ivette Bayo, Philip Reed, Cherry Cong Wang, and Marisol Silva. 2013a. Fearless Cards: A Low-Tech Solution to Help Overcome Emotional Barriers to ICT Adoption Among Marginalized Populations. The Electronic Journal of Information Systems in Developing Countries 56, 1 (April 2013), 1-15. DOI :

http://dx.doi .org/10.1002/j.1681-4835.2013.tb00397.x

[28] Ricardo Gomez, Ivette Bayo, Philip J. Reed, Cong Wang, and Marisol Silva. 2013b. Fearless cards: addressing emotional barriers to computer learning among extremely marginalized populations. In $\mathrm{CHI}$ ' 13 Extended Abstracts on Human Factors in Computing Systems on - CHI EA '13. ACM Press, Paris, France, 631. DOI : http://dx.doi .org/10.1145/2468356.2468468

[29] Amy Gonzales. 2017. Technology Maintenance: A New Frame for Studying Poverty and Marginalization. In Proceedings of the 2017 CHI Conference on Human Factors in Computing Systems - CHI '17. ACM Press, Denver, Colorado, USA, 289-294. DOI :

http://dx.doi.org/10.1145/3025453.3025475 2019-04-23.

[30] Tamy Guberek, Allison McDonald, Sylvia Simioni, Abraham H. Mhaidli, Kentaro Toyama, and Florian Schaub. 2018. Keeping a Low Profile?: Technology, Risk and Privacy among Undocumented Immigrants. In Proceedings of the 2018 CHI Conference on Human Factors in Computing Systems - CHI '18. ACM Press, Montreal QC, Canada, 1-15. DOI :

http://dx.doi.org/10.1145/3173574.3173688 2019-02-24.

[31] Donna Jeanne Haraway. 2016. Staying with the trouble: making kin in the Chthulucene. Duke University Press, Durham. 2019-08-27.

[32] Eszter Hargittai. 2002. Second-Level Digital Divide: Differences in People's Online Skills. First Monday 7, 4 (April 2002). DOI :

http://dx.doi.org/10.5210/fm.v7i4.942

[33] Serena Hillman, Alexandra Hillman, Carman Neustaedter, and Carolyn Pang. 2019. "I Have a Life": Teacher Communication \& Management Outside the Classroom. In Extended Abstracts of the 2019 CHI Conference on Human Factors in Computing Systems CHI EA '19. ACM Press, Glasgow, Scotland Uk, 1-6. DOI : http://dx.doi .org/10.1145/3290607.3312943

[34] Juan Pablo Hourcade, Daiana Beitler, Fernando Cormenzana, and Pablo Flores. 2008. Early olpc experiences in a rural uruguayan school. In Proceeding of the twenty-sixth annual CHI conference extended abstracts on Human factors in computing systems - CHI '08. ACM Press, Florence, Italy, 2503. D0I: http://dx.doi.org/10.1145/1358628.1358707 2019-06-02. 
[35] Joey Chiao-Yin Hsiao and Tawanna R. Dillahunt. 2018. Technology to Support Immigrant Access to Social Capital and Adaptation to a New Country. In Proceedings of the ACM on Human-Computer Interaction, Vol. 2. 21. 2019-07-18.

[36] Azalea Irani, Kriti Nelavelli, Kristin Hare, Paula Bondal, and Neha Kumar. 2018. Refuge Tech: An Assets-Based Approach to Refugee Resettlement. In Extended Abstracts of the 2018 CHI Conference on Human Factors in Computing Systems. ACM, LBW554. 2018-10-25.

[37] Lilly Irani, Janet Vertesi, Paul Dourish, Kavita Philip, and Rebecca E. Grinter. 2010. Postcolonial computing: a lens on design and development. In Proceedings of the 28 th international conference on Human factors in computing systems - CHI'10. ACM Press, Atlanta, Georgia, USA, 1311. DOI :

http://dx.doi.org/10.1145/1753326.1753522 2018-11-11.

[38] Azra Ismail and Neha Kumar. 2019. Empowerment on the Margins: The Online Experiences of Community Health Workers. In Proceedings of the 2019 CHI Conference on Human Factors in Computing Systems CHI '19. ACM Press, Glasgow, Scotland Uk, 1-15. DOI : http://dx.doi.org/10.1145/3290605.3300329 2019-08-28.

[39] Steven J. Jackson, Alex Pompe, and Gabriel Krieshok. 2011. Things fall apart: maintenance, repair, and technology for education initiatives in rural Namibia. In Proceedings of the 2011 iConference on-iConference '11. ACM Press, Seattle, Washington, 83-90. DOI : http://dx.doi.org/10.1145/1940761.1940773 2018-11-2.

[40] Anirudha Joshi, Ashish Ganu, Aditya Chand, Vikram Parmar, and Gaurav Mathur. 2004. Keylekh: a keyboard for text entry in indic scripts. In Extended abstracts of the 2004 conference on Human factors and computing systems - CHI '04. ACM Press, Vienna, Austria, 928. DOI: http://dx.doi.org/10.1145/985921.985950

[41] Matthew Kam, Akhil Mathur, Anuj Kumar, and John Canny. 2009. Designing digital games for rural children: a study of traditional village games in India. In Proceedings of the 27th international conference on Human factors in computing systems - CHI 09. ACM Press, Boston, MA, USA, 31. DOI : http://dx.doi .org/10.1145/1518701.1518707 2019-05-27.

[42] Matthew Kam, Divya Ramachandran, Varun Devanathan, Anuj Tewari, and John Canny. 2007. Localized iterative design for language learning in underdeveloped regions: the PACE framework. In Proceedings of the SIGCHI conference on Human factors in computing systems - CHI '07. ACM Press, San Jose, California, USA, 1097. DOI : http://dx.doi.org/10.1145/1240624.1240791 2019-7-11.

[43] Finn Kensing and Jeanette Blomberg. 1998. Participatory Design: Issues and Concerns. Computer Supported Cooperative Work (CSCW) 7, 3 (Sept. 1998),
167-185. https://doi.org/10.1023/A: 1008689307411 2018-11-30.

[44] Kai Lukoff, Cissy Yu, Julie Kientz, and Alexis Hiniker. 2018. What Makes Smartphone Use Meaningful or Meaningless? Proceedings of the ACM on Interactive, Mobile, Wearable and Ubiquitous Technologies 2, 1 (March 2018), 1-26. DOI : http://dx.doi.org/10.1145/3191754 2019-07-11.

[45] Gloria Mark, Mary Czerwinski, and Shamsi T. Iqbal. 2018. Effects of Individual Differences in Blocking Workplace Distractions. In Proceedings of the 2018 CHI Conference on Human Factors in Computing Systems CHI '18. ACM Press, Montreal QC, Canada, 1-12. DOI : http://dx. doi .org/10.1145/3173574.3173666

[46] Gary Marsden, Robert Cherry, and Alan Haefele. 2002. Small screen access to digital libraries. In $\mathrm{CHI}$ '02 extended abstracts on Human factors in computing systems - CHI '02. ACM Press, Minneapolis, Minnesota, USA, 786. DOI :

http://dx.doi.org/10.1145/506443.506597

[47] Michelle Murphy. 2015. Unsettling care: Troubling transnational itineraries of care in feminist health practices. Social Studies of Science 45, 5 (Oct. 2015), 717-737. DOI : http://dx.doi.org/10.1177/0306312715589136

[48] Joseph Nesbitt and AnnMarie Thomas. 2010. Bridging the digital divide one tweet at a time: twitter-enabled devices for family communication. In Proceedings of the 28 th of the international conference extended abstracts on Human factors in computing systems - CHI EA ' 10. ACM Press, Atlanta, Georgia, USA, 3949. DOI : http://dx.doi.org/10.1145/1753846.1754084 2019-05-27.

[49] Bryce Clayton Newell, Ricardo Gomez, and Verónica E. Guajardo. 2016. Information seeking, technology use, and vulnerability among migrants at the United States Mexico border. The Information Society 32, 3 (May 2016), 176-191. DOI :

http://dx.doi .org/10.1080/01972243.2016.1153013

[50] Chris Norval, John L. Arnott, and Vicki L. Hanson. 2014. What's on your mind?: investigating recommendations for inclusive social networking and older adults. In Proceedings of the 32nd annual ACM conference on Human factors in computing systems - CHI '14. ACM Press, Toronto, Ontario, Canada, 3923-3932. DOI : http://dx.doi.org/10.1145/2556288.2556992 2019-04-23.

[51] United States Department of Commerce National Telecommunications and Information Administration. 1995. FALLING THROUGH THE NET: A Survey of the "Have Nots" in Rural and Urban America. (1995). https://www.ntia.doc.gov/ntiahome/fallingthru.html

[52] Judith S. Olson and Wendy Kellogg (Eds.). 2014. Ways of knowing in HCI. Springer, New York. OCLC: ocn879418401. 
[53] Joyojeet Pal. 2017. CHI4Good or Good4CHI. In Proceedings of the 2017 CHI Conference Extended Abstracts on Human Factors in Computing Systems CHI EA '17. ACM Press, Denver, Colorado, USA, 709-721. DOI :

http://dx.doi.org/10.1145/3027063.3052766 2019-04-15.

[54] Anastasia N. Panagakos and Heather A. Horst. 2006. Return to Cyberia: technology and the social worlds of transnational migrants. Global Networks 6, 2 (April 2006), 109-124. DOI :

http://dx.doi.org/10.1111/j.1471-0374.2006.00136.x

[55] Lucy Pei and Bonnie Nardi. 2019. We Did It Right, But It Was Still Wrong: Toward Assets-Based Design. In Extended Abstracts of the 2019 CHI Conference on Human Factors in Computing Systems - CHI EA '19. ACM Press, Glasgow, Scotland Uk, 1-11. DOI : http://dx.doi.org/10.1145/3290607.3310434

[56] Ann Peterson Bishop and Karen E. Fisher. 2015. Using ICT design to learn about immigrant teens from Myanmar. In Proceedings of the Seventh International Conference on Information and Communication Technologies and Development - ICTD '15. ACM Press, Singapore, Singapore, 1-4. DOI :

http://dx.doi.org/10.1145/2737856.2737903

[57] James Pierce. 2012. Undesigning technology: considering the negation of design by design. In Proceedings of the 2012 ACM annual conference on Human Factors in Computing Systems - CHI'12. ACM Press, Austin, Texas, USA, 957. D0I : http://dx.doi.org/10.1145/2207676.2208540

[58] Divya Ramachandran, Matthew Kam, Jane Chiu, John Canny, and James F. Frankel. 2007. Social dynamics of early stage co-design in developing regions. In Proceedings of the SIGCHI conference on Human factors in computing systems - CHI '07. ACM Press, San Jose, California, USA, 1087. DOI : http://dx.doi.org/10.1145/1240624.1240790 2019-06-02.

[59] Elissa M. Redmiles, Sean Kross, and Michelle L. Mazurek. 2017. Where is the Digital Divide?: A Survey of Security, Privacy, and Socioeconomics. In Proceedings of the 2017 CHI Conference on Human Factors in Computing Systems - CHI'17. ACM Press, Denver, Colorado, USA, 931-936. DOI :

http://dx.doi.org/10.1145/3025453.3025673 2019-04-23.

[60] Johnny Saldaña. 2015. The coding manual for qualitative researchers. OCLC: 953858633.

[61] Nithya Sambasivan. 2019. The remarkable illusions of technology for social good. Interactions 26, 3 (April 2019), 64-66. DOI : http://dx. doi . org/10.1145/3319378 2019-09-08.

[62] Nithya Sambasivan, Ed Cutrell, Kentaro Toyama, and Bonnie Nardi. 2010. Intermediated technology use in developing communities. In Proceedings of the 28th international conference on Human factors in computing systems - CHI '10. ACM Press, Atlanta, Georgia, USA, 2583. DOI : http://dx.doi .org/10.1145/1753326.1753718 2019-03-25.

[63] Sayan Sarcar, Cosmin Munteanu, Jussi Jokinen, Antti Oulasvirta, Neil Charness, Mark Dunlop, and Xiangshi Ren. 2018. Designing Interactions for the Ageing Populations. In Extended Abstracts of the $2018 \mathrm{CHI}$ Conference on Human Factors in Computing Systems CHI '18. ACM Press, Montreal QC, Canada, 1-5. DOI : http://dx.doi.org/10.1145/3170427.3170607

[64] Sayan Sarcar, Cosmin Munteanu, Jussi P. P. Jokinen, Antti Oulasvirta, Chaklam Silpasuwanchai, Neil Charness, Mark Dunlop, and Xiangshi Ren. 2017. Designing Mobile Interactions for the Ageing Populations. In Proceedings of the 2017 CHI Conference Extended Abstracts on Human Factors in Computing Systems - CHI EA '17. ACM Press, Denver, Colorado, USA, 506-509. DOI:

http://dx.doi.org/10.1145/3027063.3027074 2019-04-26.

[65] Ben Shneiderman. 2001. Design: CUU: bridging the digital divide with universal usability. interactions 8,2 (March 2001), 11-15. DOI : http://dx.doi.org/10.1145/361897.361905 2019-04-27.

[66] Deepesh Das Shrestha. 2015. Resettlement of Bhutanese refugees surpasses 100,000 mark. (Nov. 2015). https://www . unhcr.org/news/latest/2015/11/564dded46/ resettlement-bhutanese-refugees-surpasses-100000-mark . html

[67] Geeta Shroff and Matthew Kam. 2011. Towards a design model for women's empowerment in the developing world. In Proceedings of the 2011 annual conference on Human factors in computing systems - CHI'11. ACM Press, Vancouver, BC, Canada, 2867. DOI : http://dx.doi.org/10.1145/1978942.1979368 2019-05-26.

[68] Christo Sims. 2013. Is it time to rethink 'digital inequality' (again)? AoIR Selected Papers of Internet Research 3, 0 (2013). https://firstmonday.org/ojs/ index.php/spir/article/view/8693

[69] Christo Sims. 2014. From differentiated use to differentiating practices: negotiating legitimate participation and the production of privileged identities. Information, Communication \& Society 17, 6 (July 2014), 670-682. DOI :

http://dx.doi.org/10.1080/1369118X.2013.808363 2019-09-01.

[70] Lucy Suchman and Libby Bishop. 2000. Problematizing 'Innovation' as a Critical Project. Technology Analysis \& Strategic Management 12, 3 (Sept. 2000), 327-333. DOI : http://dx.doi.org/10.1080/713698477 2018-11-17. 
[71] Emeline Therias, Jon Bird, and Paul Marshall. 2015. Más Tecnologia, Más Cambio?: Investigating an Educational Technology Project in Rural Peru. In Proceedings of the 33rd Annual ACM Conference on Human Factors in Computing Systems - CHI'15. ACM Press, Seoul, Republic of Korea, 447-456. DOI : http://dx.doi.org/10.1145/2702123.2702595 2019-04-30.

[72] Kentaro Toyama. 2011. Technology as amplifier in international development. In Proceedings of the 2011 iConference on - iConference '11. ACM Press, Seattle, Washington, 75-82. DOI :

http://dx.doi.org/10.1145/1940761. 1940772 2019-03-11.

[73] Kentaro Toyama. 2018. From needs to aspirations in information technology for development. Information Technology for Development 24, 1 (Jan. 2018), 15-36. DOI : http://dx.doi.org/10.1080/02681102.2017.1310713 2018-11-24.

[74] Panayiota Tsatsou. 2011. Digital divides revisited: what is new about divides and their research? Media, Culture \& Society 33, 2 (March 2011), 317-331. DOI : http://dx.doi.org/10.1177/0163443710393865 2019-04-08.

[75] William D. Tucker. 2004. Connecting bridges across the digital divide. In Extended abstracts of the 2004 conference on Human factors and computing systems CHI '04. ACM Press, Vienna, Austria, 1039. D0I : http://dx.doi.org/10.1145/985921.985968

[76] Alexander JAM van Deursen and Jan AGM van Dijk. 2019. The first-level digital divide shifts from inequalities in physical access to inequalities in material access. New Media \& Society 21, 2 (Feb. 2019), 354-375. DOI :

http://dx.doi.org/10.1177/1461444818797082

[77] Earnest Wheeler and Tawanna R. Dillahunt. 2018. Navigating the Job Search as a Low-Resourced Job
Seeker. In Proceedings of the 2018 CHI Conference on Human Factors in Computing Systems - CHI '18. ACM Press, Montreal QC, Canada, 1-10. D0I :

http://dx.doi.org/10.1145/3173574.3173622 2019-04-29.

[78] Earnest Wheeler, Tawanna R. Dillahunt, and Soo Young Rieh. 2017. Opportunities to Address Information Poverty with Social Search. In Proceedings of the 2017 CHI Conference Extended Abstracts on Human Factors in Computing Systems - CHI EA '17. ACM Press, Denver, Colorado, USA, 2224-2231. DOI : http://dx.doi.org/10.1145/3027063.3053167 2019-04-25.

[79] Marisol Wong-Villacres, Arkadeep Kumar, Aditya Vishwanath, Naveena Karusala, Betsy DiSalvo, and Neha Kumar. 2018. Designing for Intersections. In Proceedings of the 2018 on Designing Interactive Systems Conference 2018 - DIS '18. ACM Press, Hong Kong, China, 45-58. DOI:

http://dx.doi.org/10.1145/3196709.3196794 2019-09-10.

[80] Marisol Wong-Villacres, Neha Kumar, and Betsy DiSalvo. 2019. The Parenting Actor-Network of Latino Immigrants in the United States. In Proceedings of the 2019 CHI Conference on Human Factors in Computing Systems - CHI '19. ACM Press, Glasgow, Scotland Uk, 1-12. DOI : http://dx.doi .org/10.1145/3290605.3300914

[81] Susan Wyche, Nightingale Simiyu, and Martha E. Othieno. 2016. Mobile Phones as Amplifiers of Social Inequality among Rural Kenyan Women. ACM Transactions on Computer-Human Interaction 23, 3 (June 2016), 1-19. DOI : http://dx.doi.org/10.1145/2911982 2019-09-06.

[82] Jason C. Yip, Carmen Gonzalez, and Vikki Katz. 2016. The learning experiences of youth online information brokers. Singapore: International Society of the Learning Sciences. 2019-03-18. 